\title{
INVESTIGATIVE THERAPY OF COVID-19 CASES WITH CONVALESCENT PLASMA
}

KEY WORDS: COVID-19, convalescent plasma therapy, Remdesivir

\section{Anjan Jyoti Talukdar}

Raj Pratim Das*

Basanta Hazarika

Priyam Saikia

Tirtha Chaliha

Sangit Dutta

Achyut Chandra

Baishya
MD Assistant Prof.,Department Of Medicine, GMCH, Guwahati-32 „Dranjan.

MD Associate Prof.,Department Of Emergency Medicine, GMCH, Guwahati-32 *Corresponding Author

DM Prof., Department Of Pulmonary Medicine, GMCH, Guwahati-32

MD Assistant Prof., Department Of Anaesthesia, GMCH, Guwahati-32

MD Prof. ,Department Of Pathology, GMCH, Guwahati-32

MD Prof.,Department Of Medicine, GMCH, Guwahati-32

\section{Prof., Department Of Community Medicine, GMCH, Guwahati-32}

BACKGROUD: Covid-19 has emerged has an alarming public health crisis, putting the healthcare facilities across the globe at strain. Even after almost ten months of its identification, there exists only a few specific approved therapeutic agents for novel coronavirus disease. In this observational study, we have looked for any clinical benefits of convalescent plasma therapy in moderately severe cases of Covid-19, when added to a regimen consisting of Remdesivir, Dexamethasone and Heparin. METHODOLOGY: 528 moderately severe patients confirmed by RT-PCR test were enrolled. One dose of $200 \mathrm{~mL}$ of convalescent plasma (CP) derived from recently recovered donors with the neutralizing antibody titers above 1:640 was transfused to 268 patients as an addition to maximal supportive care and Remdesivir with steroid and heparin while 260 received Remdesivir with steroid and heparin.

RESULTS:The primary endpoint was mortality benefit. The second endpoints were the reduction in days of hospitalization, viral clearance and improvement of clinical symptoms. The median time from onset of illness to plasma transfusion was $9.55 \mathrm{~d}$ (range 6-24 d).No severe adverse effects were observed.

CONCLUSION: Our study showed that CPT could improve survival in patients when added to the standard therapy in patients with moderate Covid-19 infection. The add on therapy also significantly reduced the need for supplemental oxygen in the survivors It could potentially improve the clinical outcomes besides being a well-tolerated modality of treatment.

\section{INTRODUCTION}

The novel coronavirus or SARS-CoV-2 infection has emerged as the most dreaded pandemic of the twenty first century. The disease spread rapidly across the globe affecting major population in all continents ${ }^{1}$. Currently, there are only a few approved specific agents targeting the virus and its effects, while some drugs are still under investigation. Remdesivir have shown potential antiviral effects against Covid- $19^{2}$. The corticosteroids have come up as core treatment modality as documented by the Recovery trial ${ }^{3}$. Anti-thrombotic therapy (heparin) emerged as potential agent to combat the basic pathophysiology of SARS-CoV-2 infection, which is widespread thrombosis ${ }^{4}$.

When used as a therapeutic agent, convalescent plasma or immunoglobulins have been found to improve the survival rate of patients with SARS whose condition continued to deteriorate despite treatment with methylprednisolone. Moreover, several studies showed a shorter hospital stay and lower mortality in patients treated with convalescent plasma than those who were not treated with convalescent plasma ${ }^{5,5,7}$. The World Health Organization recommended use of CPT as an empirical therapy in 2014, in Ebola virus disease ${ }^{8}$. In 2015 CPT was part of the treatment of Middle East respiratory syndrome ${ }^{9}$.

During the 2009 pandemic of influenza $A H I N l$ virus infection, a prospective cohort study by Hung and colleagues showed a significant reduction in the relative risk of mortality (odds ratio 020 [95\% CI 0 06-0 69], $p=0$ 01) for patients treated with convalescent plasma ${ }^{10}$. A multi-center, prospective, double-blind, randomized controlled trial by Hung and colleagues showed that using convalescent plasma to treat patients with severe influenza $A$ HlNl infection was associated with a lower viral load and reduced mortality within 5 days of symptom onset
Mair-Jenkins and colleagues in a meta-analysis showed that the mortality was reduced after receiving various doses of convalescent plasma in patients with severe acute respiratory infections $^{12}$. Another meta-analysis by Luke and colleagues identified eight studies involving 1703 patients with 1918 influenza pneumonia from 1918 to 1925 who received an infusion of influenza-convalescent human blood products, which showed a pooled absolute reduction of $21 \%(95 \%$ CI $15-27 ; p<0 \quad 001)$ in the overall crude case-fatality rate at low risk of bias ${ }^{13}$.

As SARS, Middle East Respiratory Syndrome (MERS), and COVID-19 share some similarity in clinical characteristics ${ }^{14}$, CP therapy appeared as a promising treatment option for COVID-19 patients ${ }^{15}$. Patients who have recovered from COVID-19 with a satisfactory neutralizing antibody titer qualifies as a donor of CP. Nevertheless, CPT has shown variable efficacy in various clinical trials conducted around the globe, the potential clinical benefit and risk of convalescent blood products in COVID-19 remains uncertain. This observational study was carried out to look into potential clinical benefits of convalescent plasma therapy.

\section{METHODS}

\section{Study design}

This study was conducted in Covid hospital of Gauhati Medical College. Patients admitted from May to September 2020 were enrolled into the analysis. Patients who were categorized as moderate Covid-19 disease as per Ministry of Health and Family welfare (MoHFW), Government of India guidelines, were enrolled ${ }^{16}$. Any patient fulfilling criterion for severe disease or requiring admission ICU on presentation were excluded from analysis. All patients were diagnosed with RTPCR for Covid-19. Proper informed consent was obtained from the patients or legal guardians before administering convalescent plasma and Remdesivir. 
A total of 528 patients were enrolled. 268 received convalescent plasma with Remdesivir, dexamethasone and heparin and this group is referred hereafter as Group A. 260 patients received Remdesivir with dexamethasone and heparin and this group is referred as Group B in the study. All patients enrolled continued to receive the standard treatment protocol of Government of Assam that consists of Zinc 50mg OD,Vit C $500 \mathrm{mg}$ OD,Vit D 60000 IU weekly and Famotidine 20 $\operatorname{mgBD}{ }^{17}$.

\section{PLASIMA PROTOCOL}

Convalescent plasma was obtained from willing donors fulfilling the following criteria:

1.Patients with symptomatic Covid-19 infection

2.Completed 4 weeks after testing negative for Covid-19

3.Clinically stable at time of donation

4. Have a neutralizing antibody against SARS CoV-2 with a titer $>1: 160$

$200 \mathrm{ml}$ of $\mathrm{ABO} / \mathrm{Rh}$ compatible convalescent plasma was transfused into the recipients intravenous over a period of 2 hours. The patients who did not receive convalescent plasma therapy due to non-availability of compatible plasma or those who did not give consent for plasma therapy were enrolled in the comparator arm or Group B. All patients were followed throughout the period of hospitalization and clinical improvement/deterioration was noted.

The study protocol was approved by the Institutional Ethical Committee of Gauhati Medical College.

\section{RESULTS AND DISCUSSION}

Baseline Characteristics

Table I: Baseline Characteristics of the patients enrolled in the study

\begin{tabular}{|l|l|l|l|}
\hline CHARACTER & GROUP A & GROUP B & P value \\
\hline AGE (MEAN in Years) & 58.02 & 55.9 & 0.1075 \\
\hline SEX & & & \\
\hline MALE & $216(80.59 \%)$ & $195(75 \%)$ & 0.1489 \\
\hline FEMALE & 52 & 65 & \\
\hline COMORBIDITIES (TOTAL) & 215 & 146 & $<0.0001$ \\
\hline DM & 134 & 80 & $<0.0001$ \\
\hline HTN & 134 & 90 & 0.0005 \\
\hline CKD & 28 & 16 & 0.1037 \\
\hline CAD & 10 & 7 & 0.6675 \\
\hline CANCER & 4 & 5 & 0.9634 \\
\hline OTHERS & 44 & 24 & 0.0195 \\
\hline $\begin{array}{l}\text { SPO2 AT PRESENTATION } \\
\text { (MEAN) }\end{array}$ & 94.2 & 95.08 & 0.0316 \\
\hline $\begin{array}{l}\text { OXYGEN REQUIRED } \\
\text { (L/MIN) (MEDIAN) }\end{array}$ & 8.56 & 6.53 & $<0.0001$ \\
\hline $\begin{array}{l}\text { DURATION OF } \\
\text { SYMPTOMS PRIOR TO } \\
\text { HOSPITALIZATION } \\
\text { (DAYS)(MEDIAN) }\end{array}$ & 5.584 & 5.284 & 0.1075 \\
\hline $\begin{array}{l}\text { DURATION OF } \\
\text { SYMPTOMS PRIOR TO } \\
\text { CPT INFUSION } \\
\text { (DAYS)(MEDIAN) }\end{array}$ & $\begin{array}{l}\text { RANGE (6- } \\
\text { RAN }\end{array}$ & $\begin{array}{l}\text { NOPPLICAB } \\
\text { LE }\end{array}$ & \\
\hline
\end{tabular}

From May, 2020 to September, 2020, 528 moderately severe COVID-19 patients were enrolled and 268 patients received plasma transfusion. The mean age of the patients in Group $A$ was 58.02 y while it was 55.9 y in Group B. (Table I). Males constituted majority in both groups (Group A $80.59 \%$ and Group B75\%). The mean SPO2 at time of admission was $94.2 \%$ and $95.02 \%$ respectively in Group $A$ and B and the median oxygen requirement was $8.56 \mathrm{~L} / \mathrm{min}$ (range l-10) and 6.53 L/Min (1-10).

The median time from onset of symptoms to hospital admission and CP transfusion was $5.5 \mathrm{~d}$ (IQR, $4 \mathrm{~d}$ to $11 \mathrm{~d}$ ) and $5.2 \mathrm{~d}$ (IQR, $3 \mathrm{~d}$ to $9 \mathrm{~d}$ ), respectively while the median time from onset of symptoms and plasma transfusion was $9.55 \mathrm{~d}$ (IQR, $6 \mathrm{~d}$ to 24 d).
215 patients in Group A and 195 in Group B had co-morbid diseases, commonest being Diabetes Mellitus, Hypertension, Chronic kidney Disease and Coronary Artery Disease.

\section{OUTCOMES}

Table II: Outcome Measures

\begin{tabular}{|c|c|c|c|}
\hline OUTCOIMES & GROUP A & GROUP B & P-VALUE \\
\hline DEATH & $13(4.8 \%)$ & $\begin{array}{l}30 \\
(11.5 \%)\end{array}$ & \multirow{2}{*}{$\begin{array}{l}0.0081 \\
\text { (chi square } \\
=0.2695 \text { ) }\end{array}$} \\
\hline ALIVE & 255 & 230 & \\
\hline \multicolumn{4}{|l|}{ SEX } \\
\hline MALE DEATHS & 10 & 3 & \multirow[t]{2}{*}{0.6037} \\
\hline FEMALE DEATHS & 19 & 11 & \\
\hline $\begin{array}{l}\text { VIRAL CLEARANCE } \\
\text { (MEDIAN) }\end{array}$ & 12.64 & 11.56 & 0.015 \\
\hline $\begin{array}{l}\text { DURATION OF } \\
\text { HOSPITALIZATION } \\
\text { (MEDIAN) }\end{array}$ & 12.660 & 11.952 & 0.0868 \\
\hline \multicolumn{4}{|l|}{$\begin{array}{l}\text { OXYGEN } \\
\text { REQUIREMENT } \\
\text { (L/MIN) (MEDIAN) }\end{array}$} \\
\hline BASELINE & 8.56 & 6.53 & $<0.0001$ \\
\hline DAY 3 & $4.96(1-10)$ & $3.70(1-10)$ & $<0.0001$ \\
\hline DAY 7 & $2.09(0-5)$ & $2.881-7)$ & $<0.0001$ \\
\hline
\end{tabular}

$13(4.8 \%)$ patients died in Group A while 30 (11.5\%) died in Group B showing a significant mortality benefit in the patients receiving convalescent plasma therapy ( $p$ value- 0.0081 , Chisquare value with Yates correction=7.022, Relative Risk $=2.379,95 \% \mathrm{CI})$.

Female patient deaths were more in both groups (19 Vs 11 in Group A\&B), but the difference was not significant between the two groups ( $p$ value $=0.6037$, chi square value $=0.2695$ ).

Regarding virologic clearance, Group B showed early clearance (median duration of $12.46 \mathrm{~d}$ in Group A compared to $11.56 \mathrm{~d}$ in Group B, p value=0.0154, Mann-Whitney Ustatistic $=25845$ ).

The mean duration of hospitalization required was not statistically significant between the two study groups (12.66 d in Group A and $11.95 \mathrm{~d}$ in Group B, p value $=0.0868$, MannWhitney U-statistic=27786).

The survivors in CPT treated patients (Group A) showed significant improvement in terms of the amount of supplemental oxygen required to maintain a SPO $2>94 \%$. From 8.56L/Min at time of enrollment, Group A patients recorded a median SPO2 of 4.96L/Min in Day3 (compared to $3.70 \mathrm{~L} / \mathrm{Min}$ in Group B, p value $=<0.0001$, and $2.09 \mathrm{~L} / \mathrm{Min}$ in Day7 (2.88 L/Min in Group B, p value $=<0.0001)$. By day 7,40 patients were off oxygen support in group $A$ compared to 11 in Group B.

In our study, one patient developed chill and rigor following infusion of convalescent plasma and the therapy was discontinued in that case and the patient was excluded from the study. Apart from this no adverse events were noted.

In our study we found that the group of patients receiving convalescent plasma therapy in addition to Remdesivir, steroid and heparin showed significant mortality benefit (Table II) ( $p$ value $=0.0081$, relative risk $=0.4204,95 \%$ CI). Joyner et al found that transfusion of convalescent plasma is safe in hospitalized patients with COVID-19, and support the notion that earlier administration of plasma within the clinical course of COVID-19 is more likely to reduce mortality ${ }^{18}$. Rojas et al noted that by virtue of direct neutralization of the virus, control of an overactive immune system and immunomodulation of a hypercoagulable state, convalescent plasma is beneficial in treatment of Covid- 19 and that all these benefits of CP are expected to be better achieved if used in 
non-critically hospitalized patients, in the hope of reducing morbidity and mortality ${ }^{19}$. Shen et al found that transfusion of convalescent plasma led to a resolution of ground.glass opacities and consolidation in Covid-19 patients. This study indicates that convalescent plasma therapy is effective and specific for COVID.19 and is believed to be a promising state of the art therapy during COVID. 19 pandemic crisis ${ }^{20}$.

Regarding virologic clearance, Group B showed early clearance (median duration of $12.46 \mathrm{~d}$ in Group A andl $1.56 \mathrm{~d}$ in Group B). Shen et al found that viral loads decreased and became negative within 12 days after the transfusion of $\mathrm{CP}^{20}$. Similarly, Duan et al found that one dose of CP was accompanied by rapid neutralization of viremia ${ }^{20}$. Remdesivir also has role in reduction of viral load ${ }^{21}$.

The mean duration of hospitalization required was not statistically significant between the two study groups (12.66 d in Group A and $11.95 \mathrm{~d}$ in Group B, p value $=0.0868$, MannWhitney U-statistic=27786).

Our study found an important role of plasma therapy in improving hypoxia in Covid-19 patients. The survivors in the CPT treated patients (Group A) required lesser amount of supplemental oxygen, showing a significant reduction from $8.56 \mathrm{~L} / \mathrm{Min}$ at time of enrollment to a median SPO2 of 4.96L/Min on Day3 and 2.09 L/Min on Day7. Our findings are supported by Duan et al who noted significant improvement in hypoxia with the increase of oxyhemoglobin saturation within 3d of CPT infusion ${ }^{21}$.

In our study, one patient developed chill and rigor following infusion of convalescent plasma and the therapy was discontinued in that case and the patient was excluded from the study. Apart from this no adverse events were noted. The US Convalescent Plasma Expanded Access Program of 20,000 hospitalized patients in the United States with severe or lifethreatening COVID-19, found that the overall frequency of serious adverse events classified as attributable or likely secondary to convalescent plasma transfusion continued to be low $(<1 \% \text { of all transfusions })^{18}$.

Our observations suggest that convalescent plasma therapy is not only safe but an effective tool to combat moderately severe Covid-19 patients. Plasma therapy added to Remdesivir, steroid and heparin improved survival in our study group compared with those receiving only Remdesivir, steroid and heparin. The combination therapy also reduced the requirement of supplemental oxygen significantly in the survivors. However, we did not find any benefit in reduction viral load or duration of hospitalization compared to the group treated with Remdesivir, steroid and heparin.

Observations from various parts of the world have noted variable efficacy of convalescent plasma therapy on the course of Covid-19 infections but none have commented on its mortality benefits.

A randomized multicenter trial to evaluate the efficacy of plasma therapy as an add on to standard therapy in Covid-19 is needed to look into the efficacy of combination therapies that include convalescent plasma in Covid-19.

ACKNOWLEDGMENT: The authors thank Govt. of Assam, Dept. of Health\& Family welfare for infrastructure support

Financial support \& Sponsorship: The present study was supported by Gauhati Medical College \& Hospital

Conflicts of interest: The authors have no conflict of Interest

\section{REFERENCES}

1. Wang C, Horby PW, Hayden FG, Gao GF. A novel coronavirus outbreak of global health concern. The Lancet. 2020 Feb 15;395(10223):470-3.

2. Beigel JH, Tomashek KM, Dodd LE, Mehta AK, Zingman BS, Kalil AC, Hohmann E, Chu HY, Luetkemeyer A, Kline S, Lopez de Castilla D. Remdesivir for the treatment of Covid-19-preliminary report. New England Journal of
Medicine.2020 May 22

3. Di Perri G. The rationale for Low-Molecular Weight Heparin (LMWH) use in SARS-CoV-2 infection. Le infezioni in medicina. 2020 Jun 1:28(suppl 1):52-6.

4. Lai ST. Treatment of severe acute respiratory syndrome. European Journal of Clinical Microbiology and Infectious Diseases. 2005 Sep 1;24(9):583-91.

5. Soo YO, Cheng Y,Wong R, Hui DS, Lee CK, Tsang KK, Ng MH, Chan P, Cheng G, Sung JJ. Retrospective comparison of convalescent plasma with continuing high dose methylprednisolone treatment in SARS patients. Clinical microbiology and infection. 2004 Jul;10(7):676-8.

6. Cheng Y, Wong R, Soo YO, Wong WS, Lee CK, Ng MH, Chan P, Wong KC, Leung $\mathrm{CB}$, Cheng G. Use of convalescent plasma therapy in SARS patients in Hong Kong. European Journal of Clinical Microbiology and Infectious Diseases. 2005 Jan 1;24(1):44-6.

7. World Health Organization. Use of convalescent whole blood or plasma collected from patients recovered from Ebola virus disease for transfusion, as an empirical treatment during outbreaks: interim guidance for national health authorities and blood transfusion services. World Health Organization; 2014

8. Arabi Y, Balkhy H, Hajeer AH, Bouchama A, Hayden FG, Al-Omari A, AlHameed FM, Taha Y, Shindo N, Whitehead J, Merson L. Feasibility, safety, clinical, and laboratory effects of convalescent plasma therapy for patients with Middle East respiratory syndrome coronavirus infection: a study protocol.Springerplus.2015 Dec;4(1):1-8.

9. Hung IF, To KK, Lee CK, Lee KL, Chan K, Yan WW, Liu R, Watt CL, Chan WM, Lai $\mathrm{KY}$, Koo CK. Convalescent plasma treatment reduced mortality in patients with severe pandemic influenza A (HINl) 2009 virus infection. Clinical Infectious Diseases. $2011 \mathrm{Feb} 15 ; 52(4): 447-56$.

10. Hung IF, To KK, Lee CK, Lee KL, Yan WW, Chan K, Chan WM, Ngai CW, Law KI, Chow FL, Liu R. Hyperimmune IV immunoglobulin treatment: a multicenter double-blind randomized controlled trial for patients with severe 2009 influenza $\mathrm{A}(\mathrm{HlNl}$ ) infection. Chest. 2013 Aug 1;144(2):464-73.

11. Mair-Jenkins J, Saavedra-Campos M, Baillie JK, Cleary P, Khaw FM, Lim WS, Makki S, Rooney KD, Convalescent Plasma Study Group, Nguyen-Van-Tam JS, Beck CR. The effectiveness of convalescent plasma and hyperimmune immunoglobulin for the treatment of severe acute respiratory infections of viral etiology: a systematic review and exploratory meta-analysis. The Journal of infectious diseases. 2015 Jan 1;211(1):80-90.

12. Luke TC, Kilbane EM, Jackson JL, Hoffman SL. Meta-analysis: convalescen blood products for Spanish influenza pneumonia: a future H5Nl treatment? Annals of internal medicine. 2006 Oct 17;145(8):599-609.

13. Lee PI, Hsueh PR. Emerging threats from zoonotic coronaviruses-from SARS and MERS to 2019-nCoV. Journal of Microbiology, Immunology and Infection. $2020 \mathrm{Feb} 4$.

14. Chen L, Xiong J, Bao L, Shi Y. Convalescent plasma as a potential therapy for COVID-19. The Lancet Infectious Diseases.2020 Apr 1;20(4):398-400.

15. HCO O.Ministry of health and family welfare.

16. Treatment protocol for management of COVID 19. Government of Assam, 2020 version 2.0 Dated 31st August, 2020.

17. Joyner MJ, Bruno KA, Klassen SA, Kunze KL, Johnson PW, Lesser ER, Wiggins CC, Senefeld JW, Klompas AM, Hodge DO, Shepherd JR. Safety update: COVID-19 convalescent plasma in 20,000 hospitalized patients. InMayo Clinic Proceedings 2020 Sep 1 (Vol.95,No. 9,pp. 1888-1897). Elsevier.

18. Rojas M, Rodríguez Y, Monsalve DM, Acosta-Ampudia Y, Camacho B, Gallo JE, Rojas-Villarraga A, Ramírez-Santana C, Díaz-Coronado JC, Manrique R, Mantilla RD. Convalescent plasma in Covid-19: Possible mechanisms of action. Autoimmunity Reviews. 2020 May 5:102554.

19. Shen C, Wang Z, Zhao F, Yang Y, Li J, Yuan J, Wang F, Li D, Yang M, Xing L, Wei J. Treatment of 5 critically ill patients with COVID-19 with convalescent plasma. Jama.2020 Apr 28;323(16):1582-9.

20. Duan K, Liu B, Li C, Zhang H, Yu T, Qu J, Zhou M, Chen L, Meng S, Hu Y, Peng C. Effectiveness of convalescent plasma therapy in severe COVID-19 patients. Proceedings of the National Academy of Sciences. 2020 Apr 28;117(17):9490-

21. Williamson BN, Feldmann F, Schwarz B, Meade-White K, Porter DP, Schulz J, Van Doremalen N, Leighton I, Yinda CK, Pérez-Pérez L, Okumura A. Clinical benefit of remdesivir in rhesus macaques infected with SARS-CoV-2. BioRxiv. 2020 Jan 1. 